NASA Technical Memorandum 89929

\title{
Application of Scanning Acoustic Microscopy to Advanced Structural Ceramics
}

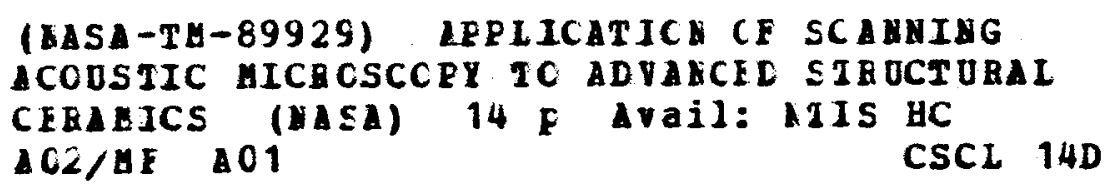

\begin{abstract}
Alex Vary and Stanley J. Klima
Lewis Research Center

Cleveland, Ohio
\end{abstract}

Prepared for the

Symposium on Characterization of Advanced Materials sponsored by the International Metallographic Society Monterey, California, July 27-28, 1987

\section{NMSA}




\title{
APPLICATION OF SCANNING ACOUSTIC MICROSCOPY
}

TO ADVANCED STRUCTURAL CERAMICS

\author{
Alex Vary and Stanley J. KTima \\ National Aeronautics and Space Administration \\ Lewis Research Center \\ Cleveland, Ohto 44135
}

\section{SUMMARY}

A review is presented on research investigations of several acoustic microscopy techniques for application to structural ceramics for advanced heat engines. Results obtained with scanning acoustic microscopy (SAM), scanning laser acoustic microscopy (SLAM), scanning electron acoustic microscopy (SEAM), and photo-acoustic microscopy (PAM) are compared. The techniques were evaluated on research samples of green and sintered monolithic silicon nitrides and silicon carbides in the form of modulus-of-rupture bars containing deliberately introduced flaws. Strengths and 1 imitations of the techniques are described with emphasis on statistics of detectability of flaws that constitute potential fracture origins.

\section{INTRODUCTION}

Monolithic silicon carbide and silicon nitride are currently the leading structural materials for use in advanced power and propulsion system components. But, although both have good high temperature strength and oxidation resistance, they currentiy exhibit low toughness (brittleness) and unacceptable variablitity in their mechantcal properties (ref. 1). The brittleness of ceramics can lead to sudden catastrophlc fallure under working stresses. These factors lead to unpredictable performance which is the most serious handicap to the use of monolithic ceramics in load-bearing structures. Moreover, these problems are aggravated by and usually traceable to poor control over flaw populations.

Monolithic ceramics are very sensitive to minute flaws so that even flaws in the 20 to $50 \mu \mathrm{m}$ size range are likely to be critical. One way to assure reliablility is to screen out ceramic parts that contain harmful flaws. Another approach is to use nondestructive evaluation (NDE) techniques for process control. This includes use of NDE techniques during processing development research to detect and to help devise ways to reduce the incidence of harmful flaws. This report describes the capabilities and 1 imitations of several acoustic microscopy techniques for detecting minute flaws that can severely reduce the reliablitity of monolithic structural ceramics.

\section{SCANNING LASER ACOUSTIC MICROSCOPY (SLAM)}

A SLAM system is depicted in figure 1, where a continuous wave train produced by an ultrasonic crystal is transmitted through a material sample. The waves are modulated by surface roughness, material texture, anomalies and flaws. Intensity and phase variations of waves reaching the opposite surface create a disturbance pattern that is duplicated on the reflective cover-sip 
coupled to the surface. The disturbance pattern is raster-scanned by a laser beam over an area approximately $2 \mathrm{~mm}^{2}$. The laser beam, modulated by the pattern, is reflected onto a photo-detector and converted into an electronic signal from which a video image is generated. The video image shows features within the material sample (cracks, volds, inclusions) that have intercepted the through-transmitted waves. The SLAM image is refreshed at video frame rates and is usually presented at a magnification of roughly $100 x$. The sample may be slid sideways to get new images at different locations. SLAM images generated by a $100 \mathrm{MHz}$ crysta 1 appear in figure 2 .

The reliablitty of SLAM for flaw detection in silicon carbide and sllicon nitride was evaluated by introducing known populations of microvoids into representative samples (ref. 2). Green ceramic powder compacts were seeded with plastic microspheres from 50 to $530-\mu \mathrm{m}$ diameter. Volds formed after volatilizing the spheres in a preheat treatment. The seeded voids remained after sintering the compacts into modulus-of-rupture (MOR) bars. The seeded microvoids were representative of natural volds that account for roughly 25 percent of fracture origins found in ceramic MOR specimens (ref. 3). The numbers of seeded volds of various sizes were sufficient for generating probability-ofdetection (POD) statistics. Results are shown in figure 3.

It is evident from figures 2 and 3 that surface preparation by polishing or grinding is needed to enhance the detectability even of near-surface voids greater than 50- $4 \mathrm{~m}$ diameter. Surface roughness affects the signal-to-noise ratio in SLAM images. Moreover, MOR bar samples with as-fired (as-sintered) surfaces show decreased flaw detectability with increased thickness. Flaw detectability also depends on the relative coarseness of the material microstructure. In silicon carbide samples flaw detectability was found to be sigifficantly less than in silicon nitride samples that had a much denser grain structure (ref. 4).

SLAM is an excellent research tool but has somewhat limited applicability to complex shapes usually found in heat engines. Access to opposing sides of a test object is needed. Applied to simple geometric shapes, SLAM does permit continuous real-time imaging. SLAM can form a basis for assessing other ultrasonic imaging methods and for analyzing wave propagation modes. It can be used to visualize wave interactions. The size and depth of some types of flaws can be determined from SLAM image diffraction patterns (ref. 5).

\section{SCANNING ACOUSTIC MICROSCOPY (SAM)}

SAM is basically a reflection C-scan technique. As shown in figure 4, SAM uses a pulse-echo piezotransducer to generate and recelve ultrasonic radiation. Usually, the test object is immersed in a liquid medium, but other versions require only a small drop of liquid to help transmit ultrasonic waves. An acoustic lens focuses the ultrasonic energy. By adjusting the distance between the transducer and test object surface it is possible to put the focal point at different planes within the object. Mechanical scanning is used to build images of features near those planes. The amplitude of the ultrasonic signal returned to the transducer from within the sample will be nil if there is no reflector or discontinuity at a given point. Should there be a void, delamination, or inclusion, the signal strength will vary according to the acoustic mismatch with the material at that location. The signal strength for each $x-y$ coordinate point is digitized and added to an image array. Upon completion of 
a frame scan, the completed image is called up on a video monitor. A SAM image generated with a transducer operating at a center frequency of $50 \mathrm{MHz}$ appears in figure 5 .

Unlike SLAM images, SAM images are not instantaneous (1.e., not produced at video frame rates). SAM images are produced by mechanical microscanners so that it may take up to $10 \mathrm{~min}$ to image a $5 \mathrm{~mm}$ square area with a $25 \mu \mathrm{m}$ line resolution. Video frame rates are possible with high-speed, acousto-mechanical drivers. Then, the scanned area must be several orders smaller. These latter SAM devices achieve higher magnifications and usually operate at transducer frequencles exceeding $1 \mathrm{GHz}$. This calls for metallurgically polished surfaces that are impractical for the inspection needs contemplated here (ref. 6).

With SAM, access only to one side of a test object and no mechanical contact are needed. SAM can be adapted to curved surfaces by means of articulated probes. SAM can be used for surface and substrate characterization. By digitizing and saving the signals for each $x-y$ coordinate point a considerable amount of flaw characterization data can be stored for future retrieval and analysis. There is no $11 \mathrm{mit}$ on part thickness but depth of penetration is primarily limited by attenuation of the high ultrasonic frequencies needed to resolve microflaws. Although much slower than SLAM, SAM produces sharper images of flaws and allows easier estimation of flaw depth. Precision in flaw definition flaw location are gained by sacrificing speed since repeated frame scans are needed with the focal spot positioned at a different depth for each successive scan.

Figure 6 compares SLAM POD data for seeded microvoids in silicon carbide and sllicon nitride MOR bars. A preliminary SAM datum is plotted in figure 6 to show the roughly tenfold increase in the depth at which $20-\mu \mathrm{m}$ diameter volds are detected by SAM. The SAM datum is based on 14 detected $20 \mu \mathrm{m}$ volds out of 14 seeded in sllicon nitride at a depth of $1000 \mu \mathrm{m}$.

\section{PHOTO-ACOUSTIC MICROSCOPY (PAM)}

A PAM system is depicted in figure 7. The sample to be inspected is enclosed in a gas (air) filled acoustic isolation cell containing a sensitive microphone. The cell contains a clear window through which a laser beam can raster scan the sample surface. The laser beam is chopped and its diameter and intensity are adjusted so that each point hit by the beam is periodically heated. This results in highly localized thermal cycling of the substrate and periodic motion of the surface. The resultant pressure fluctuations (sound waves) in the gas are sensed by the microphone. These acoustic signais are collected for each $x-y$ coordinate position of the laser beam. The signals are used to generate maps (images) of material variations and flaws. The magnitude and phase of the acoustic waves are related to thermal property variations and any flaws that are present near the surface. The depth to which flaws can be detected depends on the material's thermal diffusion length (ref. 7 ).

PAM is readily adapted to complex shapes by designing appropriate isolation cells to contain them. Of the techniques mentioned so far, only PAM is essentially noncontacting (SLAM and SAM required liquid coupling). Conceptually, because it does not need liquid couplants that would be detrimental, PAM should be applicable to green samples. But PAM has a serious drawback because laser beams with intensities sufficient to generate strong acoustic waves can 
mar the surface along the scan lines. Subsequent sintering of the marred samples apparently causes cracks in the scanned areas that do not appear in the unscanned areas. Hence, PAM seems inappropriate for green ceramics. Moreover, continued scanning of green samples tends to release gases that coat the cell window and occlude the laser beam.

The spatial resolution of PAM images can be made comparable to that of either SLAM or SAM, but the resolution is obtained by sacrificing scan speed. For the same spatial resolution. PAM is the slowest of the three techniques. The ability to detect small flaws depends on scan line density and scan speed. The laser scan speed is $11 \mathrm{mited}$ by thermal inertia. The beam must dwell long enough at each point to produce a fixed number of thermal oscillations. It may take roughly $4 \mathrm{hr}$ to $\mathrm{scan}$ a $1 \mathrm{~cm}$ square area with a line resolution of $25 \mu \mathrm{m}$.

Surface-connected pores and inclusions $25 \mu \mathrm{m}$ and larger were detected in sintered silicon nitride. Subsurface pores and inclusions $35 \mu \mathrm{m}$ and larger were detected to $70 \mu \mathrm{m}$ below the surface. Voids $200 \mu \mathrm{m}$ in diameter and $200 \mu \mathrm{m}$ below the surface were missed. Additional detection capabilities are cited in figure 8 which shows a PAM image of an as-fired silicon nitride sample. In PAM as in SLAM images background noise tends to be high, apparently because of surface roughness, material microstructural coarseness, and nonresolvable flaw populations.

\section{SCANNING ELECTRON ACOUSTIC MICROSCOPY (SEAM)}

A SEAM system is depicted in figure 9. An electron beam raster scans and cyclically heats micron diameter areas on the sample surface. To allow electron beam current flow, it is necessary that the sample be housed in a high vacuum enclosure which is usually shared with a scanning electron microscope (SEM) system. Then, the system operates in two modes: SEM and SEAM. The SEM mode will produce a conventional backscatter electron image of the sample surface. In the SEAM mode the electron beam is of higher intensity and cyclically modulated, usually at frequencies in the range from $100 \mathrm{~Hz}$ to $10 \mathrm{kHz}$. As each spot in the rastered area is heated, acoustic emission waves are generated within the sample. These thermally induced acoustic emissions are modulated by flaws and other imperfections. The resultant signals are sensed by a piezoelectric crystal bonded to the sample, usually to the face opposite the one being scanned. SEM and SEAM images of the same area of a silicon carbide sample appear in figure 10.

The SEAM technique is certainly appropriate for materials research and for inspecting microelectronic circuit components and simllar articles. Ceramics and other nonconductors need to be coated with a conducting layer to attract the beam electrons. A carbon deposit on silicon carbide or silicon nitride samples also enhances image contrast. The need for a high vacuum environment can pose a problem for some types of ceramic parts, especially if they tend to outgas. SEAM images can be produced at rates intermediate between SLAM and PAM. The image of a $5 \mathrm{~mm}$ square area can be generated in roughiy $1 \mathrm{~min}$. The line resolution of SEAM is of the order of $5 \mathrm{\mu m}$. The spatial resolution of SEAM images depend on the thermal wavelength while the depth of detection depends on the thermal diffusion length in the material (ref. 8).

Preliminary investigations on silicon carbide and silicon nitride samples indicate that SEAM readily images superficial pits, nodules, and natural 
cracks. Surface-connected cracks emanating from knoop indentations were resolvable down to $10 \mu \mathrm{m}$ of length. In stilicon carblde seeded volds of $500 \mu \mathrm{m}$ dlameter were readtly imaged to a depth of $550 \mu \mathrm{m}$ whtle $200 \mu \mathrm{m}$ diameter volds at a depth of $300 \mu \mathrm{m}$ were missed. In silicon nitride seeded volds of $130 \mu \mathrm{m}$ dlameter were missed at a depth of $200 \mu \mathrm{m}$.

\section{DISCUSSION}

The four acoustic microscopy techniques compared in this paper have the ability to detect minute flaws in monolithic ceramics. The problem is to define the relative strengths and 1 imitations of the techniaues. Ideally, each technique should be evaluated in terms of probability of detection (POD) statistics. Otherwise, it is impossible to assert the essential merit of any given technique over another. Accomplishing this proves to be quite difficult because known populations of different kinds of likely flaws need to be systematically embedded in representative test samples. One frequentiy-occurring failure-causing flaw type can be represented by artificia y implanted microvoids. This report covers POD statistics for only one tecinnique, namely SLAM, to illustrate its microvold detection capability. The SLAM example provides a touchstone for assessing the relative merits of the remaining acoustic microscopy techniques discussed herein.

Acoustic microscopy techniques should be considered for resolving flaws in the range from $10 \mu \mathrm{m}$ to several hundred microns. To achleve sufficient spatial resolution it is necessary to restrict the area to be imaged, typicaliy from $1 \mathrm{~mm}^{2}$ to about $1 \mathrm{~cm}^{2}$. Although there may be compeling reasons to inspect certain critical areas to the $10 \mu \mathrm{m}$ level of resolution, it is currentiy impractical to demand that every square millimeter of a ceramic heat engine part be inspected to that level. Searching for minute flaws and attempting to resolve each one can lengthen inspection time beyond acceptable bounds. This situation demands that careful consideration be given to optimum inspection strategies. These strategies should be guided by analytical identification of those loci that merit detalled inspection for minute flaws.

Although SAM appears to be the best technique for sintered ceramics no single acoustic microscopy technique can be cited as the preferred one and none of the techniques can be eliminated from consideration. If a technique is not sultable for hardware inspection, then it may be preferred as a research tool. Each technique has at least one desirable feature lacking in the others. For example. SAM gives better flaw detection and definition than SLAM, but SLAM gives immediate images while SAM takes more time to image the same area.

The findings presented in this paper were obtained through research conducted at or under contract to the NASA Lewis Research Center. Each acoustic microscopy technique was viewed relative to its applicability to green state and fully densified (e.g., sintered) ceramic components. Convenience in examining parts having complex shapes was also considered. Techiniques that do not require contact probes are preferred for ease of inspection and, particulariy, to avoid perturbing green state compacts. Ultrasonic methods usually require probes that make contact through a coupling medium. Noncontact methods that use lasers for producing and sensing ultrasonic waves are attractive alternatives. Of the methods described herein PAM uses a laser beam to produce ultrasonic waves while SLAM uses a laser beam to detect ultrasonic signals that have propagated through a part. 
At this writing, there exists no single acoustic microscopy technique that provides totally practical "laser-in, laser-out" ultrasonic flaw imaging. One technique that offers noncontact laser imaging capability is the so-called mirage technique. In the mirage technique a normally incident chopped laser beam heats a spot on the surface. A second laser beam that crosses the first while just skimming parallel to the surface is deflected by the air lens formed due to heating. The deflection is related to the flaws or substrate anomalies at the heated spot (ref. 9). Other noncontact approaches belonging to this thermal wave imaging genera utilize infrared emission or probe beam reflection to detect flaws and anomalies. These latter techniques are under study and have reported resolutions of the order of $1 \mu \mathrm{m}$. Of course, this resolution capablitity is won at the expense of long times needed to produce an image. Moreover, they are subject to effects of surface roughness, curvature, adsorbed layers, and binders/volatiles in green state materials.

\section{CONCLUSION}

This paper reviewed acoustic microscopy techniques suitable for flaw detection and imaging in monolithic ceramics. The capabilities and limitations of four techniques were described and compared: scanning laser acoustic microscopy (SLAM), scanning acoustic microscopy (SAM), photo-acoustic microscopy (PAM), and scanning electron acoustic microscopy (SEAM). Although the review given herein was not comprehensive, it did attempt to indicate the nature and current advantages and disadvantages of the aforementioned techniques. The main conclusion is that although SAM appears to be a versatile high resolution detection technique, it would be inappropriate to exclude the others from consideration in special cases or as means to augment or corroborate SAM. It was also pointed out that acoustic microscopy is by nature time-consuming and highly dependent on factors like surface roughness whenever flaws of the order of $30 \mu \mathrm{m}$ or less are sought. This demands that use of acoustic microscopy techniques be based on carefuliy considered strategles for their application to actual hardware.

\section{REFERENCES}

1. New Structural Materials Technologies: Opportunities for the Use of Advanced Ceramics and Composites, OTA-TM-E-32, (Office of Technology Assessment, Washington, D.C., 1986).

2. G.Y. Baaklint and D.J. Roth, J. Mater. Res. I, 457 (1986).

3. W.A. Sanders and G.Y. Baaklint, Ceram. Eng. Sct. Proc. I, 839 (1986). (NASA TM-87251).

4. D.J. Roth, S.J. Klima, J.E. Kiser, and G.Y. Baaklini, Mater. Eval. 4, 762 (1986).

5. E.R. Generazlo and D.R. Roth, Mater. Eval. 44, 863 (1986).

6. M. Nikoonahad, Research Techniques in Nondestructive Testing, Vol. 7, R.S. Sharpe, ed., (Academic Press, London, 1984), pp. 217-257. 
7. R.L. Thomas, J.J. Pouch, Y.H. Wong, L.D. Favro, P.K. Kuo, and A. Rosencwaig, J. App 1. Phys. 51, 1152 (1980).

8. A. Rosencwaig, Photoacoustics and Photoacoustic Spectroscopy, (John Wiley and Sons, New York, 1980).

9. L.J. Inglehart, R.L. Thomas, and J. Schuldies, J. Nondestr. Eval. 1, 287 (1980).

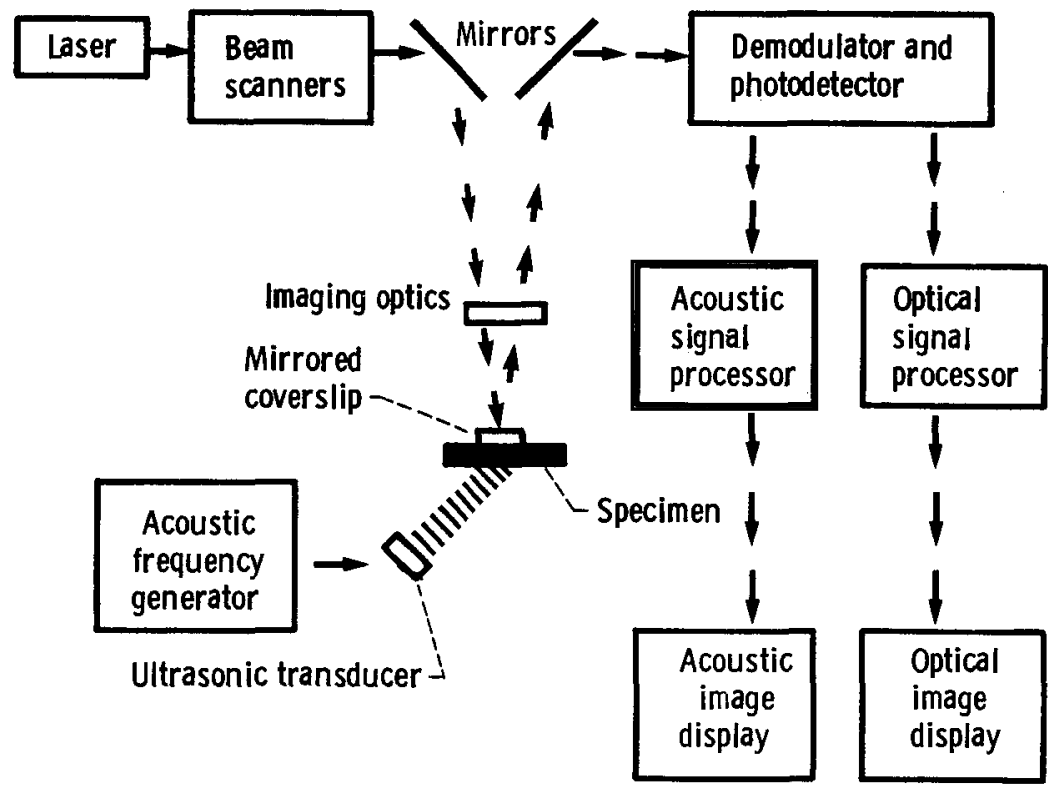

(a) Schematic of SLAM system.

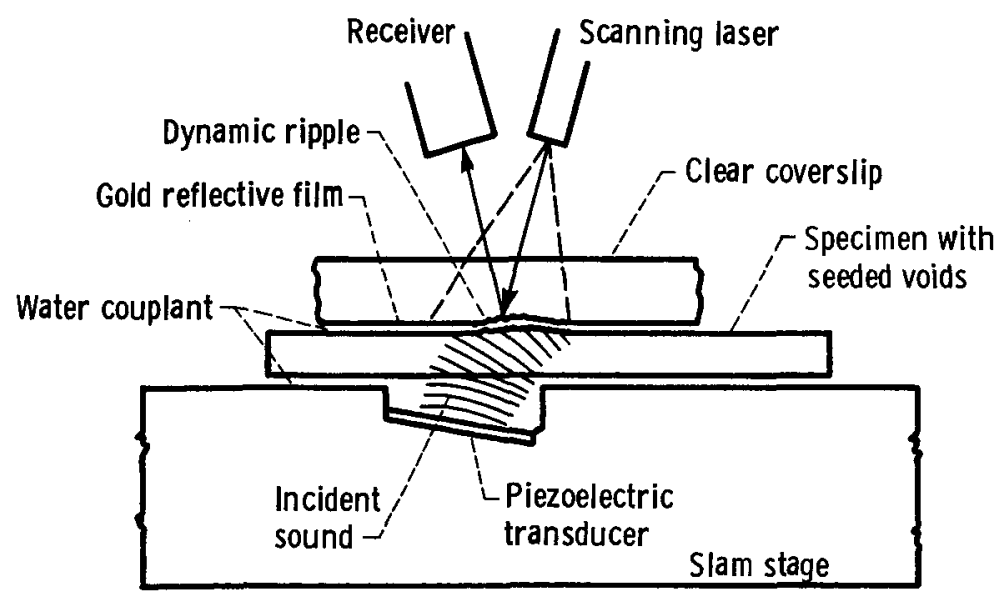

(b) Detail of specimen stage.

FIGURE 1. - DIAGRAM OF SCANNING LASER ACOUSTIC MICROSCOPE (SLAM). 


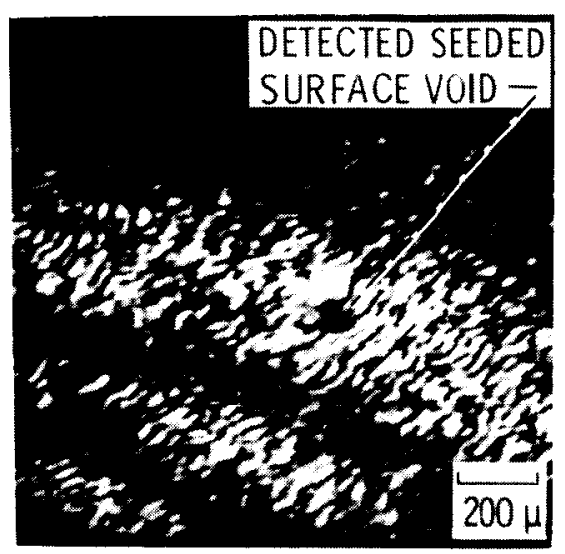

AS-FIRED BAR (SLAM)

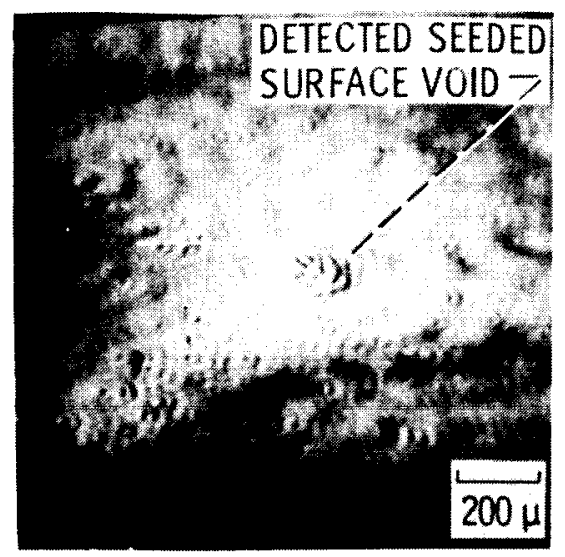

AFTER POLISHING (SLAM)

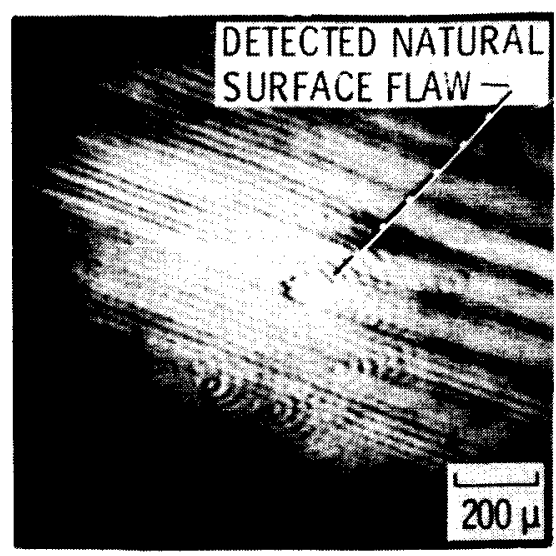

DIAMOND-GROUND BAR (SLAM)

\section{II $\mu$ ORIGINAL PAGE IS \\ OF POOR QUALITY}

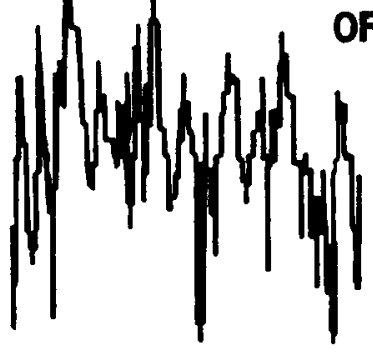

$200 \mu$

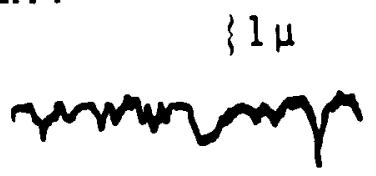

$200 \mu$
$\{1 \mu$

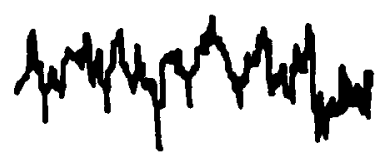

$200 \mu$

AS -FIRED SURFACE PROFILE

POLISHED SURFACE PROFILE

DIAMOND-GROUND SURFACE PROFILE

FIGURE 2 - REPRESENTATIVE SLAM IMAGES OF FLAWS IN SINTERED SILICON

CARBIDE SPECIMENS SHOWING INCREASED FLAW DETECTABILITY AFTER

SURFACE ROUGHNESS IS REDUCED BY POLISHING .

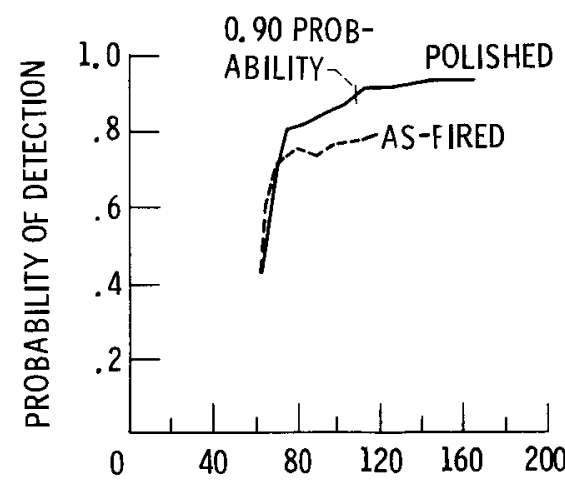

(a) $2 \mathrm{~mm}$ thick.

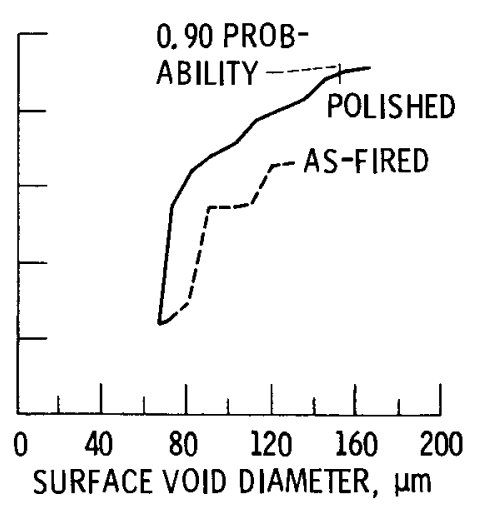

(b) $3 \mathrm{~mm}$ thick.

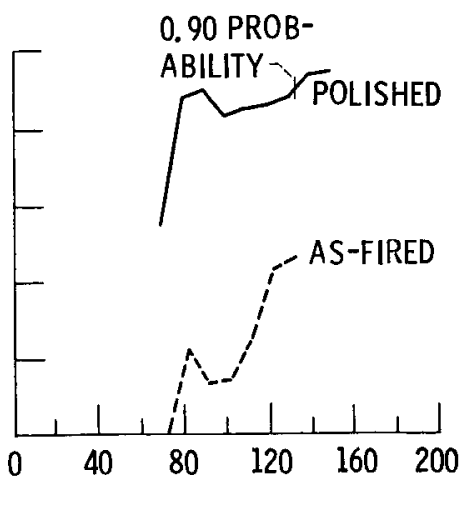

(c) $4 \mathrm{~mm}$ thick.

FIGURE 3. - REPRESENTATIVE PROBABILITY OF DETECTION (POD) CURVES BASED ON SEEDED VOID POPULATIONS SHOWING EFFECT OF SURFACE CONDITION AND SPECIMEN THICKNESS ON DETECTION OF VOIDS IN SINTERED SILICON NITRIDE USING SLAM. 


\section{ORIGINAL PAGE IS \\ OF POOR QUAI:ITY}

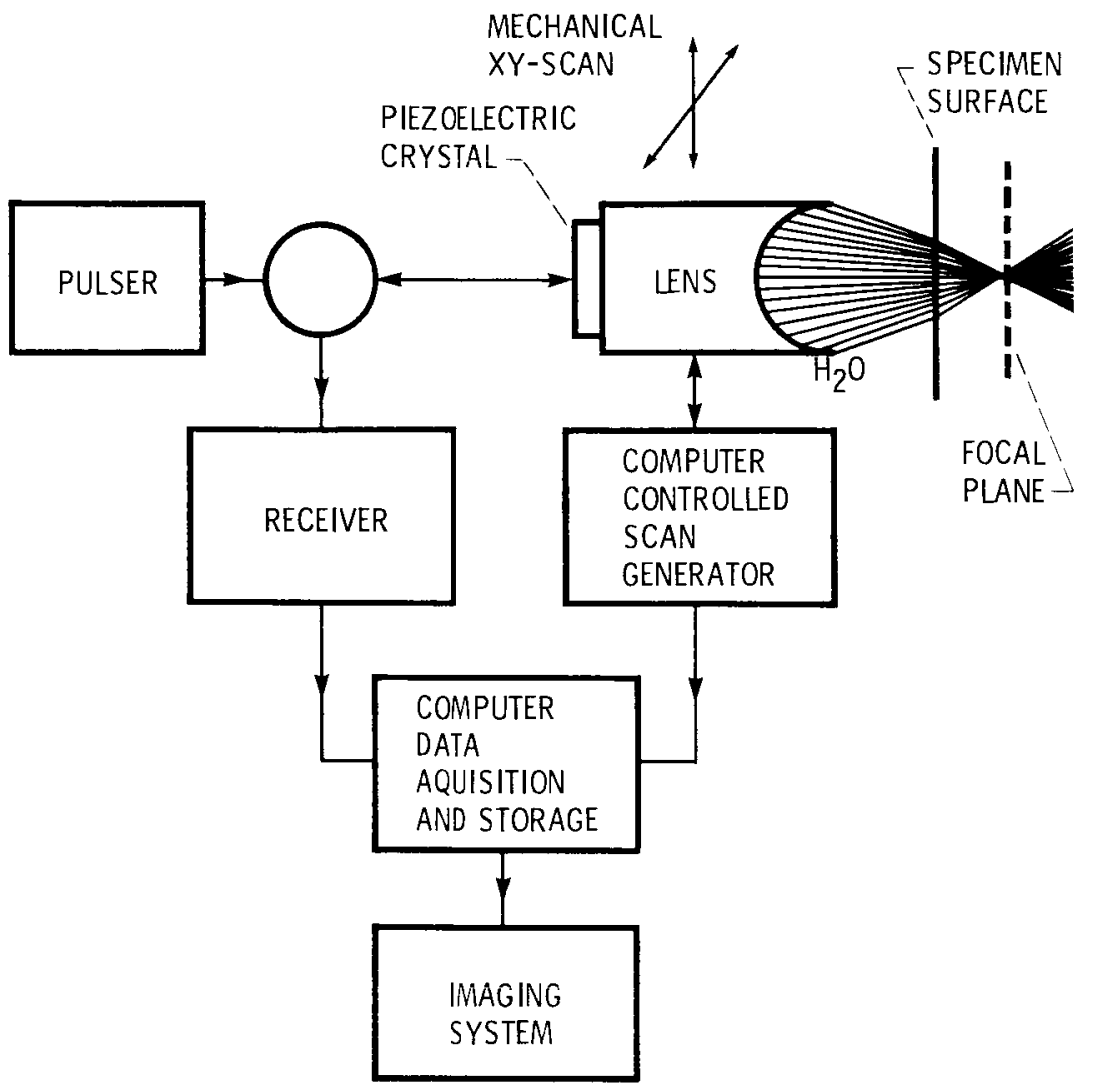

FIGURE 4. - DIAGRAM OF SCANNING ACOUSTIC MICROSCOPE (SAM) SYSTEM.
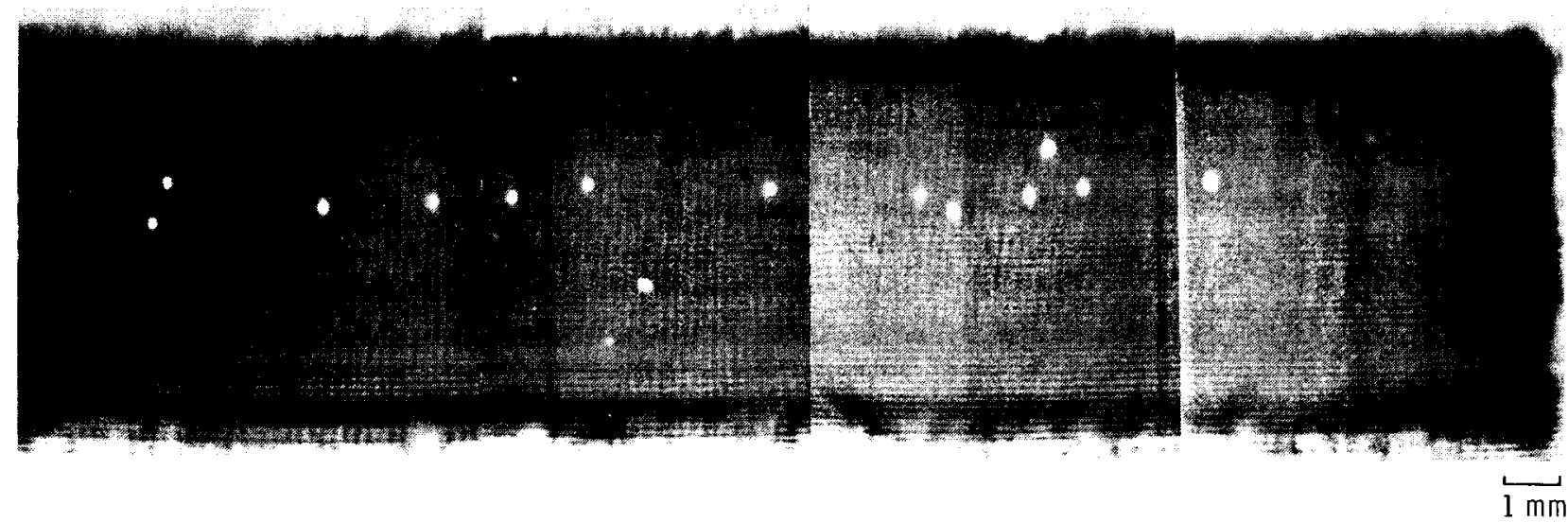

FIGURE 5. - REPRESENTATIVE SAM IMAGES OF VOIDS IN SILICON NITRIDE MODULUS OF RUPTURE (MOR) SPECIMEN. SEEDED VOIDS $20 \mathrm{~mm}$ DIAMETER WERE I $\mu \mathrm{m}$ DEEP. SPECIMEN SURFACE WAS DIAMOND GROUND. IMAGES OF THE VOIDS APPEAR LARGER THAN THEIR TRUE SIZE BECAUSE OF SIGNAL PROCESSING ENHANCEMENT. 


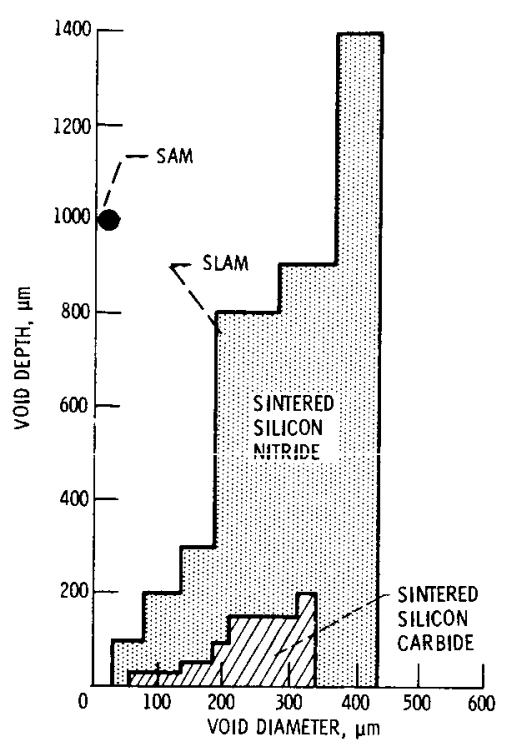

FIGURE 6. - COMPARISON OF INTERNAL VOID DETECTION CAPABILITIES OF SAM AND SLAM. DATUM FOR SAM IS FOR FOURTEEN $20 \mu \mathrm{m}$ DIAMETER SEEDED VOIDS IN SILICON NITRIDE. DATA FOR SLAM ARE FOR 90 percent PROBABILITY OF DETECTION AT 95 percent CONFIDENCE LIMIT.

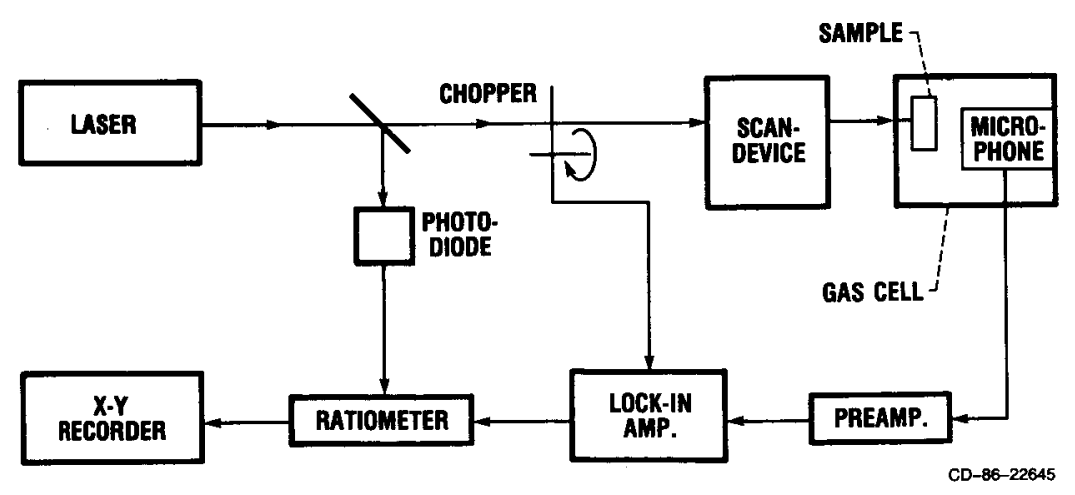

FIGURE 7. - DIAGRAM OF PHOTO-ACOUSTIC MICROSCOPY (PAM) SYSTEM. 

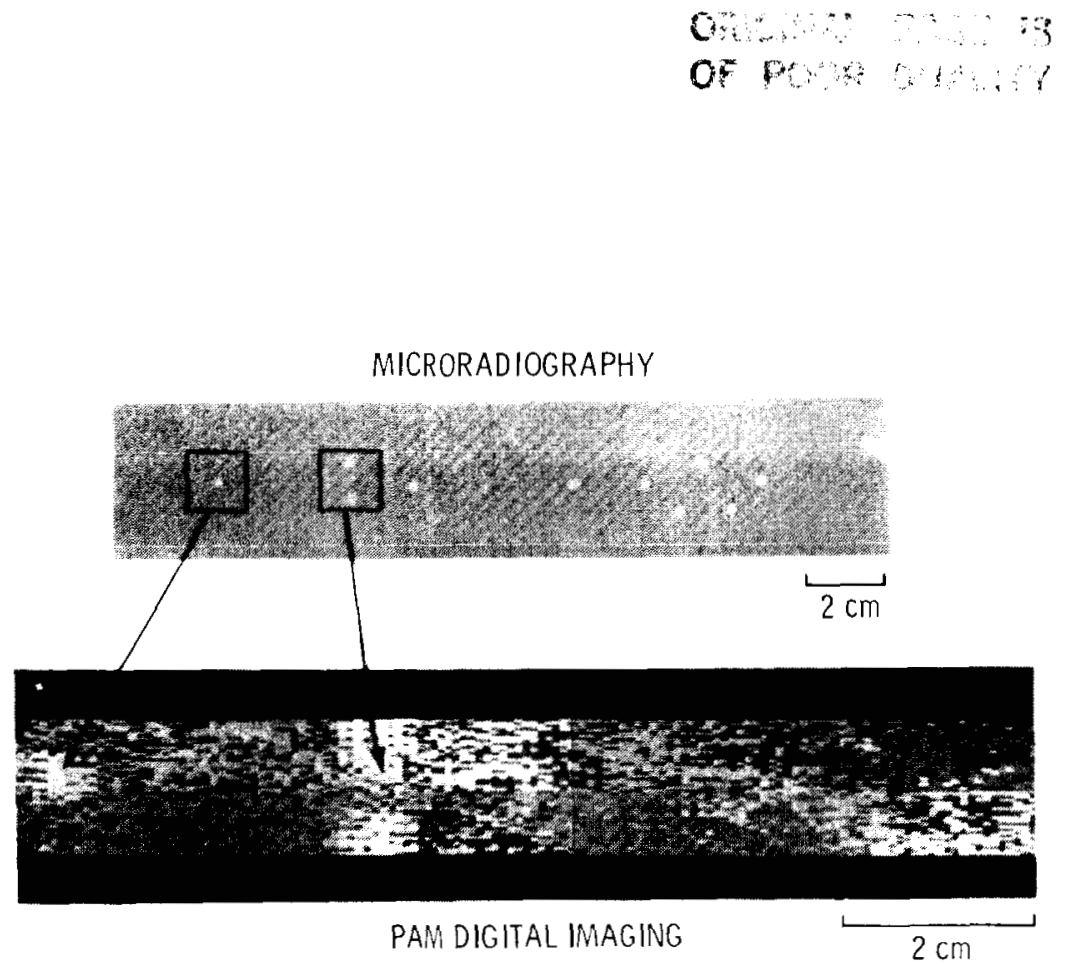

FIGURE 8. - DIGITIZED PAM IMAGE SHOWING DETECTABILITY OF SEEDED INTERNAL VOIDS IN AS-FIRED SILICON CARBIDE MOR BARS, RADIOGRAPH IS INSERTED TO SHOW WHICH VOIDS WERE DETECTED OR MIS SED. VOIDS DETECTED BY PAM WERE $450 \mu \mathrm{m}$ diam. $270 \mu \mathrm{m}$ DEEP. VOIDS MISSED BY

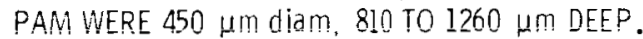

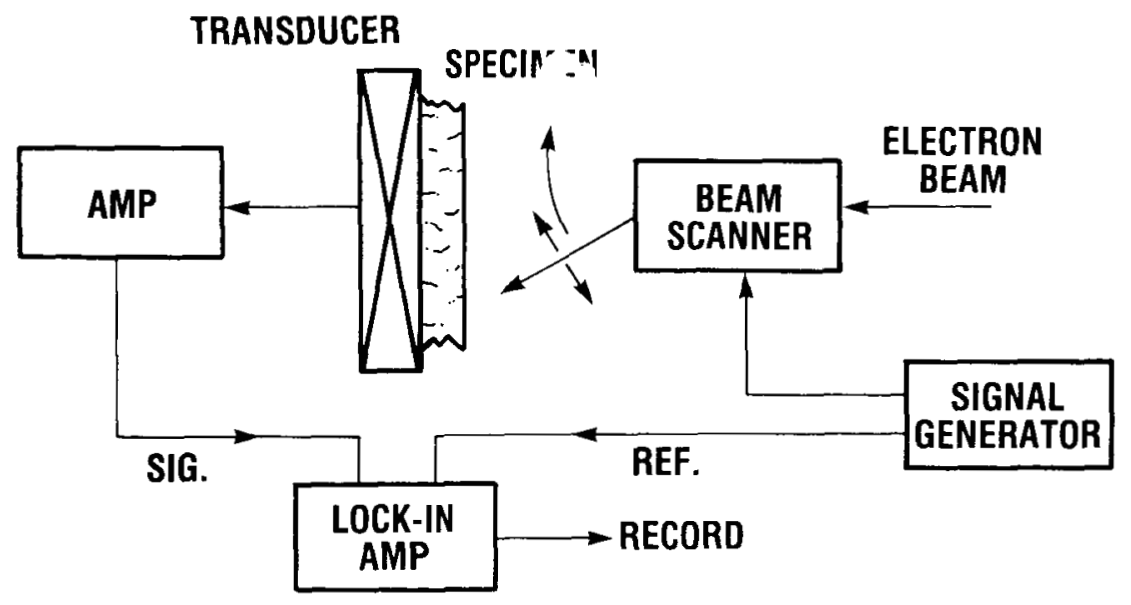

$\mathrm{CD}-86-226.44$

FIGURE 9. - DIAGRAM OF SCANNING ELECTRON ACOUSTIC MICROSCOPE (SEAM). 


\section{OF $\cos 6 \sin :$}

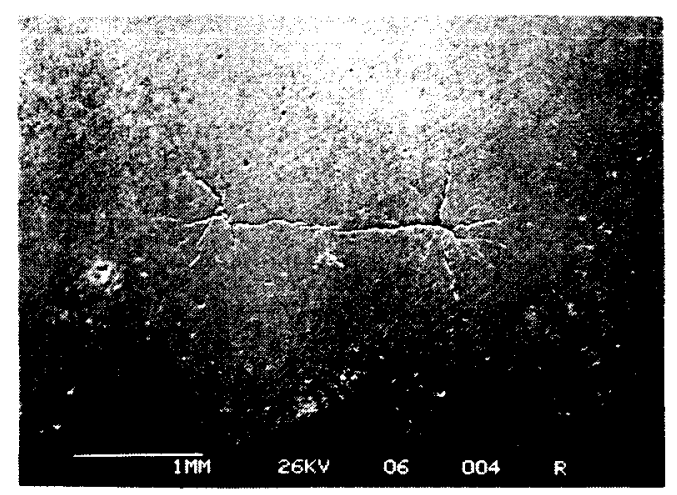

SEM IMAGE (SURFACE)

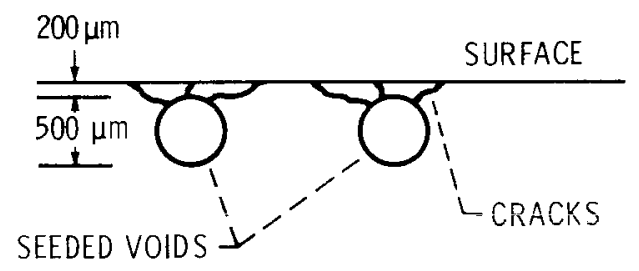

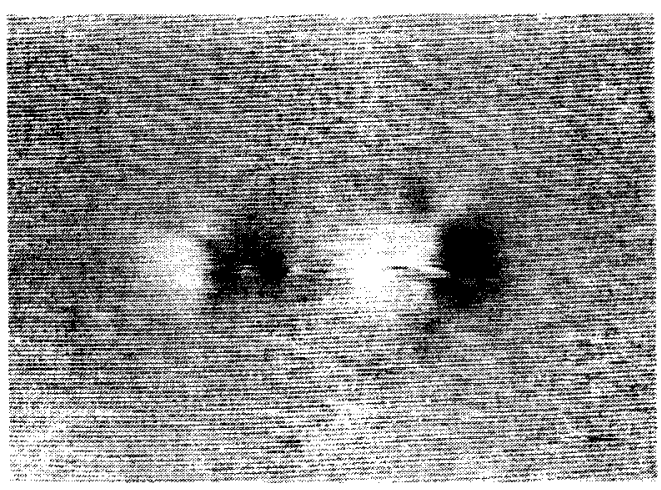

SEAM IMAGE (SUBSURFACE)

$1000 \mu \mathrm{m}$

SCALE: BOTH IMAGES

CD-85-18069

FIGURE 10. - COMPARISON OF SEAM IMAGES OF SUBSURFACE VOIDS AND SCANNING ELECTRON MICROSCOPE (SEM) IMAGES OF ASSOCIATED SURFACE CRACKS IN SILICON CARBIDE MOR BAR. 


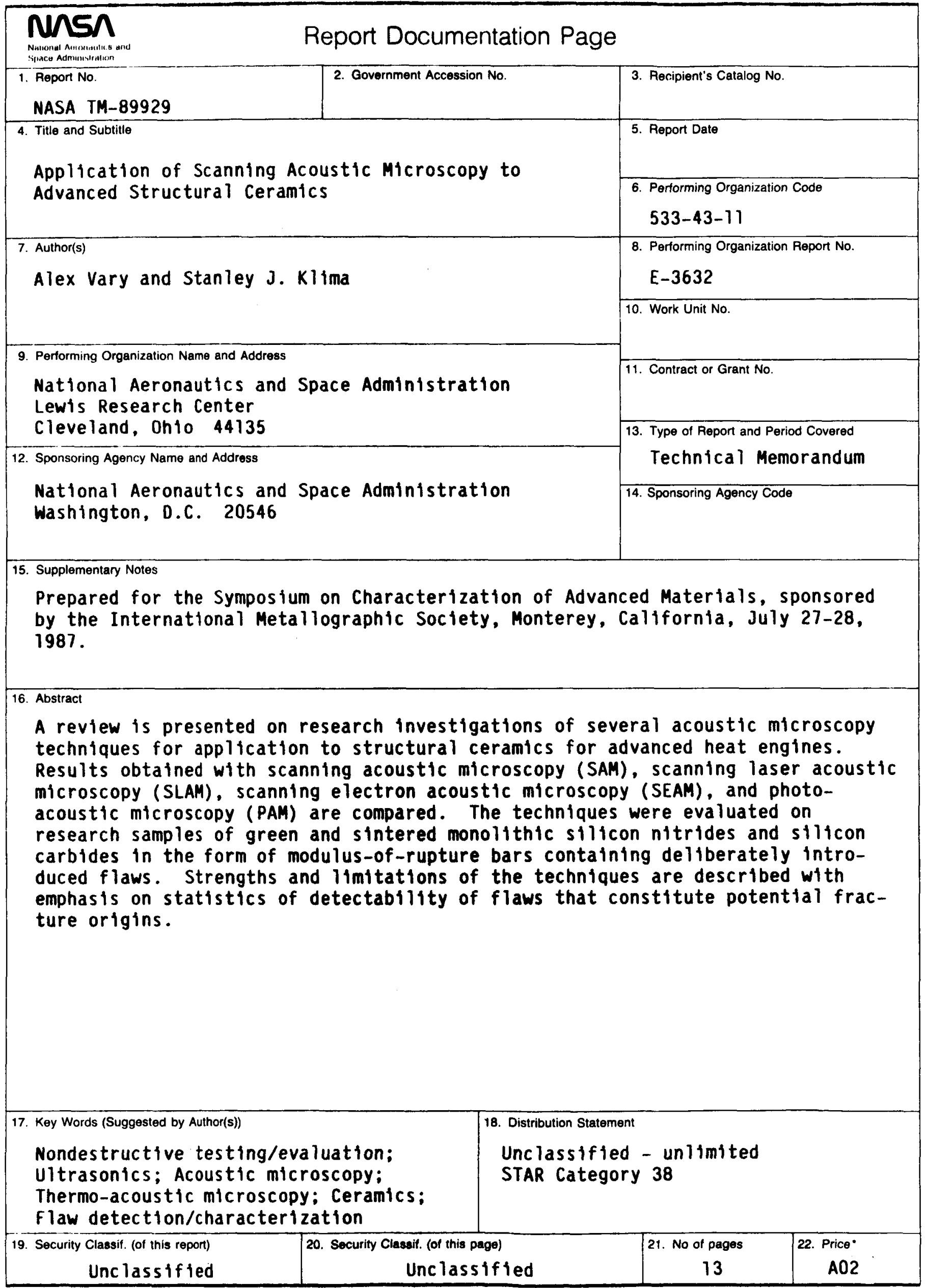

